\title{
Cellular immunity to cartilage aggrecan core protein in patients with rheumatoid arthritis and non-arthritic controls
}

Nicola J Goodstone, Mark C Doran, Roderick N Hobbs, Robin C Butler, Josh J Dixey, Brian A Ashton

\begin{abstract}
Objective-To identify antigen(s) among purified deglycosylated aggrecan peptides spanning the chondroitin sulphate domain that may be responsible for the initiation or perpetuation of the autoimmune responses in rheumatoid arthritis (RA).

Methods-Aggrecan was purified from human articular cartilage and deglycosylated with either bacterial glycosidases or trifluoromethanesulphonic acid (TFMS). Twelve overlapping peptides (15 residues) spanning the chondroitin sulphate domain with $\mathrm{N}$-terminal residues offset by three amino acids were synthesised. $T$ cell responses to these antigens in RA patients and age matched controls were assessed in vitro by antigen specific $T$ cell proliferation assays.

Results-Enzymically deglycosylated aggrecan (EDA) stimulated proliferation of $T$ cells isolated from the peripheral blood in a greater proportion of patients with RA than controls. In a subset $(12 \cdot 5 \%)$ of RA patients, the magnitude of stimulation lay outside the control range. $T$ cell proliferative responses to TFMS treated aggrecan were greater than, but well correlated with, responses to EDA. T cells from 15 patients were also stimulated with the pooled synthetic peptides. Four of seven patients who demonstrated $T$ cell reactivity to EDA (seven of 15) also showed enhanced $T$ cell proliferation to synthetic peptides.

Conclusion-These data suggest that an autoantigenic $\mathbf{T}$ cell epitope may lie within the chondroitin sulphate domain of aggrecan.
\end{abstract}

(Ann Rheum Dis 1996; 55: 40-46)
Stimulation by an in vivo autoantigen(s) may play a part in initiating or perpetuating chronic immune responses in rheumatoid arthritis (RA), ${ }^{1}$ and though several potential autoantigens have been proposed and studied, there is as yet no definite evidence in favour of any of them. Self limiting inflammatory arthritis can be induced in several animal models by immunisation with proteoglycans (PGs), and has been shown to be $T$ cell dependent by the transfer of disease to susceptible irradiated animals using isolated $T$ cell lines and clones. ${ }^{2-6}$ Cellular responses to PGs have been described in the peripheral blood, synovial fluid, and inflamed synovia from patients with RA. $^{7-9}$ The large aggregating $P G$, aggrecan, is a major structural component of the articular cartilage extracellular matrix ${ }^{10}$ and a candidate autoantigen for involvement in the pathogenesis of RA. ${ }^{11}$

Human aggrecan (fig 1) has two globular domains (G1 and G2) comprising the $\mathrm{N}$-terminus, separated from a G3 globular domain at the C-terminus by an extended glycosaminoglycan (GAG) rich domain. ${ }^{12}$ The GAG attachment region can be further subdivided into a keratan sulphate (KS) domain and two chondroitin sulphate (CS) domains (CS-1 and CS-2). The two CS domains have distinct repeating primary sequences containing many Ser-Gly dipeptides which serve as potential CS substitution points. The CS chains within the CS-1 domain are evenly distributed because of a highly conserved repeating sequence (19 repeats) of 19 amino acid residues [EVLET(A or T)APGVEDISGLPSG], while in the CS-2 domain they are arranged in clusters.

Whether autoimmune responses to collagen type II or the components of the PG aggregate are a primary phenomenon or the result of joint destruction attributable to another mechanism

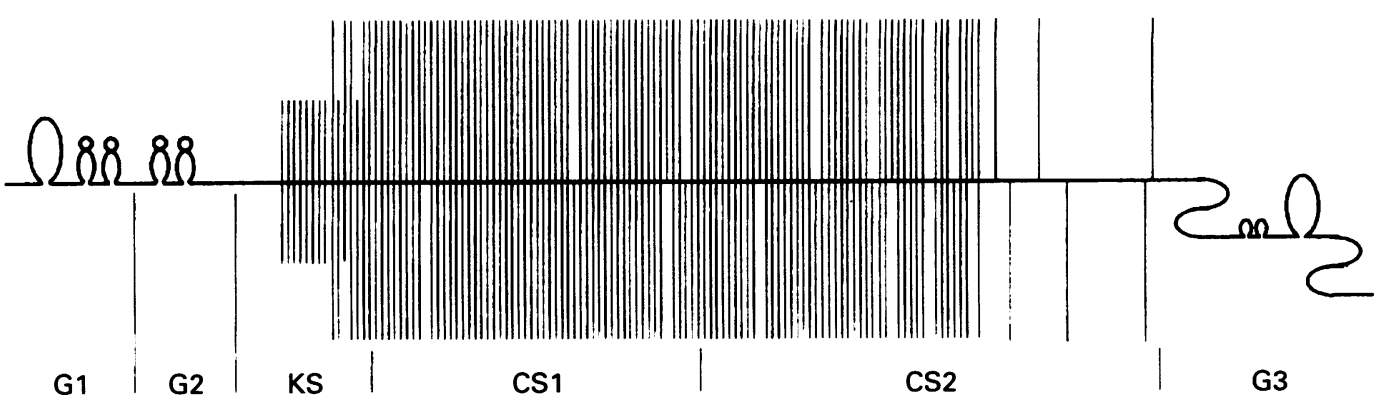

Figure 1 Schematic diagram showing the domain structure of human aggrecan. G1, G2, and G3 are globular domains, with $G 2$ and $G 3$ separated by an extended glycosaminoglycan ( $G A G$ ) attachment region. This $G A G$ attachment region is further subdivided into a region mainly substituted with keratan sulphate (KS) and two regions mainly substituted with chondroitin sulphate (CS1 and CS2). 
remains to be established. In RA cartilage, metachromatic staining decreases early in the disease process, reflecting a loss of PGs or structural changes in the PG aggregate. ${ }^{13}$ PG depletion appears to precede collagen degradation $^{14}$ and in diseased cartilage is related to the excessive production and activation of proteolytic enzymes, including metalloproteinases and serine proteinases. ${ }^{15}$ Immunoreactive fragments of the PG aggregate, including those derived from the GAG rich region of aggrecan have been detected in pathological synovial fluid samples. ${ }^{16} 17$ The antigenic properties of released aggrecan fragments may have an important role in the pathogenesis of RA and perpetuation of chronic autoimmune responses in genetically susceptible individuals.

Several studies have suggested that an auto/ arthritogenic epitope(s) lies within the GAG attachment region of aggrecan. One group ${ }^{18}$ have demonstrated that $\mathrm{T}$ cells obtained from $\mathrm{Balb} / \mathrm{c}$ mice immunised with aggrecan of various species responded to short sequences located within the CS region. Studies by Goodacre et $a l^{19}$ indicated that the CS region of human aggrecan contains cryptic $\mathrm{T}$ cell recognition sites. The significance of the presence of the GAG chains, which may somehow hide the presentation of pathogenic epitopes to the immune system in vivo, remains unclear.

We have recently shown ${ }^{20}$ that cellular immunity to cartilage link protein is found in a greater proportion of patients with inflammatory arthritis than non-arthritic age matched controls. In order to test the hypothesis that $\mathrm{T}$ lymphocyte specificity for an epitope(s) in aggrecan may be a common mechanism for the in vivo activation and expansion of peripheral blood mononuclear cells (PBMC), we isolated PBMC from patients with RA and examined their proliferative responses to purified deglycosylated aggrecan and synthetic peptides spanning the CS-1 domain.

\section{Patients and methods}

REAGENTS AND CONTROL ANTIGENS/MITOGENS Sephacryl S-500 high resolution (HR) was obtained from Pharmacia LKB Biotechnology (Sweden). Trifluoromethanesulphonic acid (TFMS), guanidinium hydrochloride $(\mathrm{GuHCl})$ and chondroitinase $A B C$ were obtained from Sigma Chemicals, Poole, Dorset, UK. Keratanase (endo- $\beta$-D-galactosidase from Pseudomonas spp) and ${ }^{3} \mathrm{H}$-thymidine were purchased from ICN Biomedicals Ltd, Oxfordshire, UK. Anisole and caesium chloride were procured from BDH Laboratory Supplies, Merck Ltd, Leicestershire, UK. All other chemicals used were of analytical grade. Tuberculin purified protein derivative (PPD) or tetanus toxoid served as control antigens and were obtained from Evans Medical Ltd, Liverpool; concanavalin A (Sigma Chemicals) was used as a positive control mitogen. Monoclonal antibody $12 / 21 / 1 / C / 6,{ }^{21}$ which recognises an epitope common to the $\mathrm{Gl}$ and G2 domains on aggrecan core protein, was a kind gift of Dr Bruce Caterson.
PATIENTS AND CONTROLS

All patients studied fulfilled the 1987 American Rheumatism Association revised criteria for definite or classical RA. ${ }^{22}$ There were 48 patients with RA (11 men and 37 women), aged 30-78 years (mean 57 (SD 11) years), and 32 control subjects (five men and 27 women), aged $21-83$ years (mean 52.6 (15) years).

ISOLATION OF PBMC

Peripheral blood was collected into sterile heparinised tubes. PBMC were isolated by Ficoll-Hypaque density gradient centrifugation over Lymphoprep (Nycomed, Sweden), washed twice with RPMI 1640 (GIBCO BRL, UK), and viable cells counted using Trypan blue. PBMC were resuspended at $10^{6}$ cells $/ \mathrm{ml}$ in RPMI 1640 supplemented with $2 \mathrm{mmol}$ L-glutamine, $100 \mathrm{~g} / \mathrm{ml}$ streptomycin, $100 \mathrm{U} / \mathrm{ml}$ penicillin and $10 \%$ heat inactivated autologous serum.

PREPARATION OF HUMAN ARTICULAR CARTILAGE PROTEOGLYCAN

Human articular cartilage was obtained from femoral heads and knees at surgery. PG aggregates were extracted from finely minced tissue in $4 \mathrm{~mol} \mathrm{GuHCl}$ buffered with $0.1 \mathrm{~mol}$ potassium acetate $\mathrm{pH} 5 \cdot 8$, in the presence of proteinase inhibitors, and purified in a caesium chloride density gradient as described by Bayliss et $a .^{23}$ The A1D1 fraction was chromatographed on Sephacryl S-500 HR in $4 \mathrm{~mol} \mathrm{GuHCl}$ buffered with $0 \cdot 1 \mathrm{~mol}$ potassium acetate $\mathrm{pH} 5 \cdot 8$, at a flow rate of $45 \mathrm{ml} / \mathrm{h}$. The eluate was monitored at $280 \mathrm{~nm}$ and fractions $(3 \mathrm{ml})$ collected and assayed for protein content (BCA Kit, Pierce Chemicals Co, Rockford, IL, USA), hexuronate, ${ }^{24}$ and reactivity with the monoclonal antibody, 12/21/1/C/6. Fractions containing aggrecan monomer were pooled, dialysed and freeze dried.

ENZYMIC DEGLYCOSYLATION OF PURIFIED

AGGRECAN MONOMER

Purified freeze dried aggrecan was dissolved $(10 \mathrm{mg} / \mathrm{ml})$ in $0.1 \mathrm{~mol}$ Tris- $\mathrm{HCl} \mathrm{pH} 7 \cdot 4$, and enzyme deglycosylated at $37^{\circ} \mathrm{C}$ for three hours in the presence of proteinase inhibitors with chondroitinase $\mathrm{ABC}(1 \mathrm{U} / \mathrm{mg})$ and keratanase $(0.25 \mathrm{U} / \mathrm{mg})$ as described by Oike et al. ${ }^{25}$ Digested material was chromatographed on Sephacryl S-500 HR equilibrated with phosphate buffered saline $\mathrm{pH} 7 \cdot 4$, at a flow rate of $45 \mathrm{ml} / \mathrm{h}$. Fractions $(3 \mathrm{ml}$ ) were assayed for protein content and reactivity with the monoclonal antibody 12/21/1-C-6. EDA containing fractions were pooled and concentrated using Microsep centrifugal concentrators (10 kDa cut off) (Filtron Corporation).

CHEMICAL DEGLYCOSYLATION OF PURIFIED AGGRECAN MONOMER

The deglycosylation of aggrecan was modified from a method by Edge et al. ${ }^{26}$ Lyophilised 
aggrecan, dried for 48 hours in vacuo over phosphorus pentoxide, was dissolved in precooled TFMS/anisole $(2: 1, \mathrm{v} / \mathrm{v})$ at $5 \mathrm{mg} / \mathrm{ml}$ with stirring under nitrogen in a 'Reactivial' (Pierce Chemical Co, Rockland, IL, USA) at $0^{\circ} \mathrm{C}$. After a two hour incubation, the reaction was terminated by adding two volumes of diethyl ether precooled to $-40^{\circ} \mathrm{C}$ and three volumes of ice cold $50 \%(\mathrm{v} / \mathrm{v})$ aqueous pyridine. The precipitate was redissolved by vortexing the mixture and then the ether phase was discarded. The density of the aqueous phase was adjusted to $1.5 \mathrm{~g} / \mathrm{ml}$ with caesium chloride to separate the chemically deglycosylated aggrecan (CDA) from glycosylated material by density gradient centrifugation in the Beckman VTi45 angle tube rotor (Beckman Ultracentrifuge, Model L7-55) at $101000 \mathrm{~g}_{\mathrm{av}}$ at $18^{\circ} \mathrm{C}$ for 66 hours. The gradient was split into six fractions (C6 top to $\mathrm{C} 1$ bottom) and subsequently assayed for protein and hexuronate content. The low buoyant density protein rich fractions $(1 \cdot 3-1 \cdot 35 \mathrm{~g} / \mathrm{ml})$ were dialysed and lyophilised.

ELECTROPHORESIS AND IMMUNOBLOTTING OF DEGLYCOSYLATED AGGRECAN

Samples of EDA/CDA and molecular weight standards (range 6-200 kDa) (Novex Experimental Technology, San Diego, CA, USA) were dissolved in reducing sample buffer containing $10 \%$ (w/v) sodium dodecyl sulphate (SDS), $0 \cdot 1 \%$ (w/v) bromophenol blue, $20 \%$ (v/v) glycerol, and 5\% (v/v) $\beta$-mercaptoethanol and heated at $100^{\circ} \mathrm{C}$ for three minutes. SDSpolyacrylamide gel electrophoresis (PAGE) on $4-20 \%$ (w/v) Tris-glycine polyacrylamide gradient gels was performed using the Xcell Mini-cell Module (Novex), and the discontinuous buffer system of Laemmli. ${ }^{27} \mathrm{~A}$ combined Coomassie blue-silver stain method was performed essentially as described by De
Moreno et al. ${ }^{28}$ Electrophoretically separated samples in an unstained gel were transferred onto nitrocellulose membranes in $12 \mathrm{mmol}$ Tris-96 mmol glycine buffer $\mathrm{pH} 8 \cdot 3$, containing $20 \%(\mathrm{v} / \mathrm{v})$ methanol as described by Towbin $e t a l,{ }^{29}$ and probed with 12/21/1/C/6.

\section{SYNTHETIC PEPTIDES}

A set of synthetic, overlapping peptides spanning the consecutive 19 mer repeats within the chondroitin sulphate domain (CS-1) between residues 999 and 1360 were prepared. The $19 \mathrm{mer}$ was selected after analysis of the human aggrecan sequence using TSites software (Medimmune Inc, USA). The software showed that the 19 mer contains a sequence with a high amphipathic index. Seven peptides were synthesised (fig 2), 15 amino acids long and offset at their $\mathrm{N}$-terminal by three amino acids (two amino acids for the last pair). Five more peptides were synthesised in which residue 6 (threonine, T) of the $19 \mathrm{mer}$ was replaced with an alanine (A) to cover degeneracy in this residue over the repeat sequences (fig 2). The peptides were synthesised on polyethylene pins using the Cleavable Peptides Kit (Cambridge Research Biochemicals, UK) and cleaved into sterile 0.1 mol sodium carbonate buffer, $\mathrm{pH} 8.3$. Peptides were assessed for purity by reverse phase high performance liquid chromatography using a Waters Model 600E System Gradient Controller (Millipore Waters Corporation, USA) high performance liquid chromatograph equipped with a Waters Model 484 Absorbance Detector, and capillary electrophoresis using a Waters Quanta 4000 Capillary Electrophoresis System (Millipore Corporation, Marlborough, MA, USA) controlled by Millennium 2010 Chromatography Manager software (Millipore). Peptides were aliquoted and stored frozen $\left(-70^{\circ} \mathrm{C}\right)$.

19 mer repeat

19 mer repeat EVLET T A P G V E I S G L P S G EVLE T T A P G V E D I S G L P S G

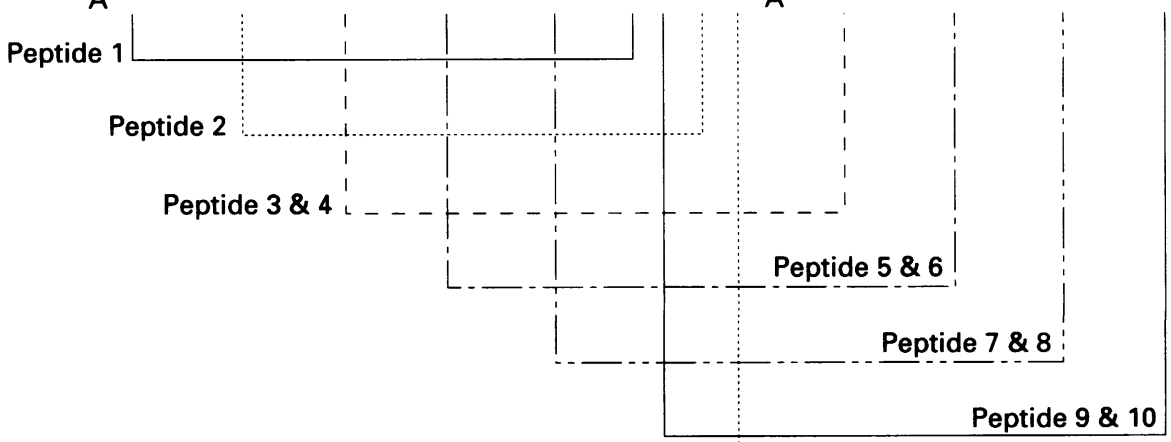

Peptide $11 \& 12$

Peptide 1 APGVEDISGLPSGEV Peptide 2 VEDISGLPSGEVLET Peptide 3 ISGLPSGEVLETTAP Peptide 4 ISGLPSGEVLETAAP Peptide 5 LPSGEVLETTAPGVE Peptide 6 LPSGEVLETAAPGVE
Peptide 7 GEVLETTAPGVEDIS Peptide 8 GEVLETAAPGVEDIS Peptide 9 LETTAPGVEDISGLP Peptide 10 LETAAPGVEDISGLP Peptide 11 TTAPGVEDISGLPS Peptide 12 TAAPGVEDISGLPS

Figure 2 Two sequences of 19 amino acid residues from the chondroitin sulphate attachment region of aggrecan core protein aligned side by side, with C-termini on the right. Peptides of 15 amino acids were spread across the aligned sequences. Twelve peptides and their numbers are illustrated, pooled into two batches for testing (1-6 and 7-12). 
ANTIGEN SPECIFIC T CELL PROLIFERATION ASSAYS

The PBMC were cultured in sextuplet at either $2 \times 10^{5}$ cells/well or $1 \times 10^{5}$ cells/well $(200 \mu \mathrm{l})$ in microtitre plates with or without enzymically deglycosylated aggrecan (EDA) 10 or $20 \mu \mathrm{g} / \mathrm{ml}$, chemically deglycosylated aggrecan (CDA) $10 \mu \mathrm{g} / \mathrm{ml}$, tuberculin PPD $50 \mathrm{U} / \mathrm{ml}$, tetanus toxoid $1 / 10000$, concanavalin A $1 \mu \mathrm{g} / \mathrm{ml}$, or synthetic peptides. The concentration of deglycosylated aggrecan used was selected on the basis of pilot studies (data not shown). Synthetic peptides were pooled into two groups (1-6 and 7-12) and added to give final concentrations of $500 \mathrm{nmol}$ and $1000 \mathrm{nmol}$ of each peptide. Cultures were incubated at $37^{\circ} \mathrm{C}$ in $5 \%$ carbon dioxide in air for five days and pulsed with $0.5 \mu \mathrm{Ci} /$ well of ${ }^{3} \mathrm{H}$-thymidine for the last six hours. Cells were harvested onto 96 well filter plates (Unifilter, Canberra-Packard) using a microtitre plate harvester (Filtermate 196, Canberra-Packard), and uptake of labelled thymidine was determined as counts per minute (cpm) using a liquid scintillation counter (TopCount Microplate Scintillation counter, Canberra-Packard Instrument Company).

\section{STATISTICAL ANALYSIS}

Lymphocyte responses are expressed as a mean stimulation index (SI) which represents the ratio of ${ }^{3} \mathrm{H}$-thymidine incorporated into stimulated cells to that incorporated into unstimulated cells. A response was arbitarily defined as positive when SI values were $>1.5$ and the level of ${ }^{3} \mathrm{H}$-thymidine was significantly greater than in the control wells $(p<0.05$; Mann-Whitney $U$ test). The proportion of individuals in a particular group demonstrating such positive responses was compared using the Fischer's exact test and the ranges of the responses seen in each group were compared using the Mann-Whitney $U$ test. A control range was defined as the mean $\pm 2 \mathrm{SD}$ of normalised control SI values and the 95\% confidence intervals (CI) of the upper level established. The numbers of individuals with responses outside the control range in each group were compared using Fischer's exact test. The correlation between $T$ cell proliferative responses to enzymically and chemically deglycosylated aggrecan was determined using linear regression analysis and the significance of the differences in responses of this group of patients to EDA and CDA was assessed by the Wilcoxon matched pairs test. Statistical analyses were performed using the statistical software package; Statgraphics (STSC, USA).

\section{Results}

ELECTROPHORESIS AND IMMUNOBLOTTING OF DEGLYCOSYLATED AGGRECAN CORE PROTEIN EDA ran as single band with a mean molecular weight of 225 (SD $2 \cdot 13) \mathrm{kDa}(\mathrm{n}=6)$ on SDS-PAGE gels stained with Coomassie blue (fig 3) and no further bands were seen after silver enhancement. On Western blotting, this band reacted with the monoclonal antibody $12 / 21 / 1 / \mathrm{C} / 6$. Treatment of the aggrecan

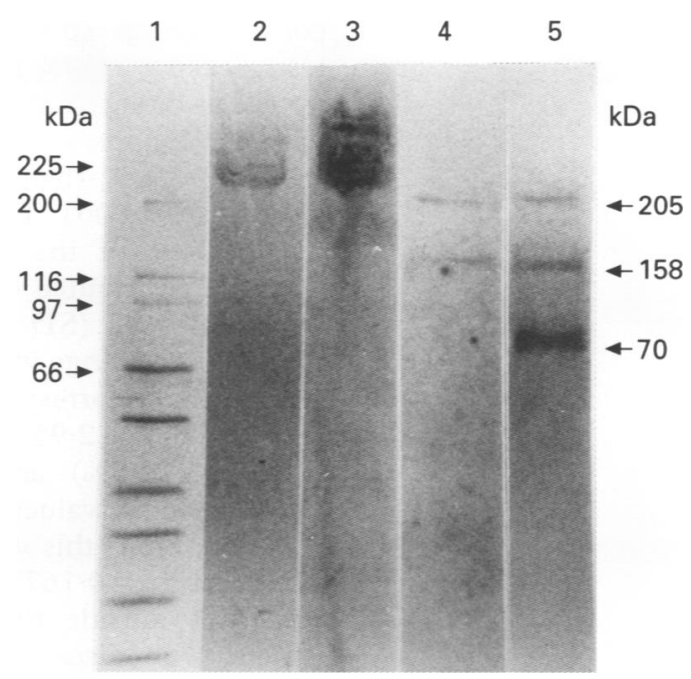

Figure 3 SDS-PAGE (lanes 2 (EDA) and $4(C D A)$ ) and Western blot probing with 1/C/6 (lanes 3 (EDA) and $5(C D A))$ of enzymically and chemically deglycosylated aggrecan core protein $(5 \mu \mathrm{g}$ ) loaded on a 4-20\% polyacrylamide gradient gel with molecular weight standards (lane 1).

with TFMS yielded two components (fig 3) with apparent mean molecular weights of $205(2 \cdot 6) \mathrm{kDa}(\mathrm{n}=4)$ and $158(3) \mathrm{kDa}(\mathrm{n}=4)$. Silver enhancement revealed a third component with a mean molecular weight of 70 (2) $\mathrm{kDa}(\mathrm{n}=4)$. When an unstained gel was immunoblotted and probed with the monoclonal antibody $12 / 21 / 1 / \mathrm{C} / 6$, all three components of the $\mathrm{CDA}$ reacted with the antibody, indicating the presence of an epitope common to both the $\mathrm{G} 1$ and $\mathrm{G} 2$ domains of aggrecan core protein (fig 3). Chemical deglycosylation did not significantly alter the ability of $12 / 21 / 1 / \mathrm{C} / 6$ to bind to core protein, as indicated by the immunoblot.

\section{T CELL RESPONSES TO EDA}

Figure 4 summarises the results of antigen stimulation with EDA in the PBMC of patients with RA and the age matched controls. The stimulation indices of the patient group were significantly greater than were observed in the

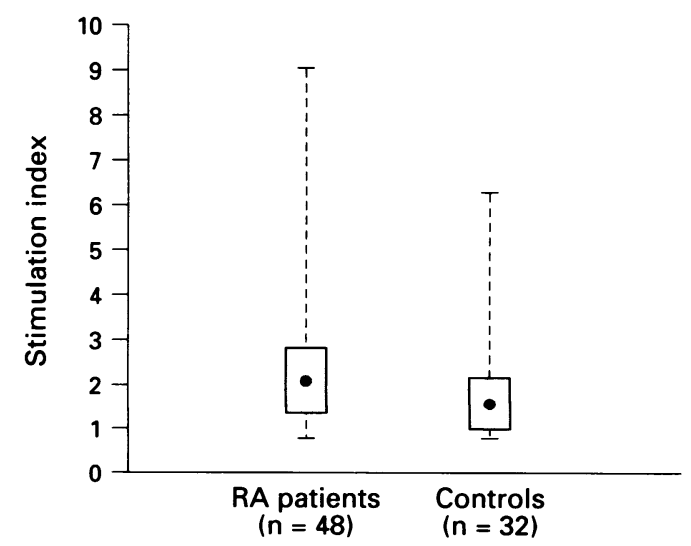

Figure 4 Box whisker plot illustrating the range of stimulation index (SI) values obtained for proliferative responses of PBMC from $R A$ patients and age matched controls to EDA. = Geometric mean; box encloses interquartile range (range of SI comprising the $50 \%$ of individuals with SI closest to the mean (25\% above and $25 \%$ below the mean)); dashed line = range. 
control group $(p<0.02$, Mann-Whitney $U$ test). Taking a $50 \%$ increase in ${ }^{3} \mathrm{H}$-thymidine uptake as biologically significant, the incidence of such responses was greater in the patient group (33/48) than in the control group $(11 / 30)(p<0.001$, Fischer's exact test). The natural logs of the control SI values were normally distributed $\left(\chi^{2} 0.86, p=0.354\right)$ with a mean of 0.41 (SD 0.48 ). An upper limit of the reference range was set at $2 \mathrm{SD}$ above the mean, which corresponded to an SI value of 3.94 (95\% CI 2.95 to $5 \cdot 25$ ). Six of the 48 patients $(12.5 \%)$ and one of 30 controls (3.3\%) had SI values greater than the upper reference limit; this was not significant at the $5 \%$ level $(p=0 \cdot 167)$. All six patients with responses outside the reference range were female, with disease duration of at least 10 years. There was no relationship between the responses to EDA and the medications taken or the age of the patient.

T CELL RESPONSES TO ENZYMICALLY AND CHEMICALLY DEGLYCOSYLATED AGGRECAN Figure 5 shows that a good linear correlation between the SI values to both preparations of deglycosylated aggrecan was obtained in patients and controls. However, it can be seen that, because several patients demonstrated greater responses to $\mathrm{CDA}$ than to EDA, the slope of the line plotted using the response seen in patients is greater than that using responses seen in controls, though the difference between the patient and control groups in the responses to the two preparations of deglycosylated aggrecan was not significant ( $p>0.05$; Wilcoxon pairs test). In addition, this comparison confirms that proliferative responses to EDA were not the result of contamination following digestion with bacterial glycosidases.

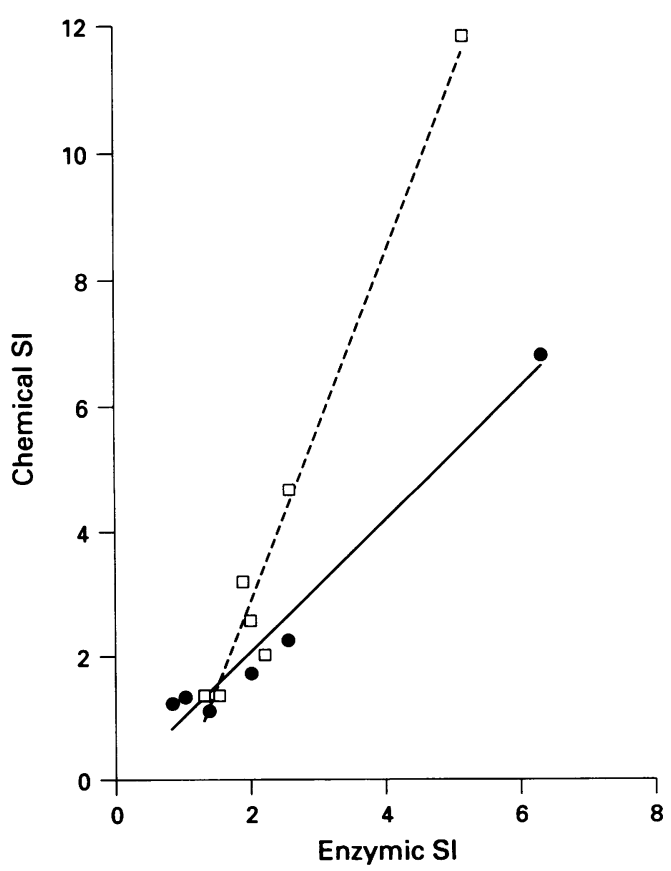

Figure 5 Linear regression of the SI values to chemically deglycosylated aggrecan core protein $(C D A)$ versus those to enzymically deglycosylated aggrecan core protein $(E D A)$ in $R A$ patients ( $(n=9)$ and controls $(O)(n=6)$.
T CELL RESPONSES TO EDA AND SYNTHETIC PEPTIDES SPANNING THE CS- 1 DOMAIN PBMC $\left(1 \times 10^{5}\right.$ cells/well $)$ from 15 RA patients were challenged with EDA $10 \mu \mathrm{g} / \mathrm{ml}$ and 12 synthetic peptides pooled into two groups (1-6 and 7-12) at two concentrations: $500 \mathrm{nmol}$ and $1000 \mathrm{nmol}$. Of the patients tested, seven of 15 demonstrated positive responses to EDA defined as a stimulation index value $>1.5$. In addition, four of these seven patients responding to the EDA also showed significantly increased proliferative responses to the synthetic peptides, but none of the patients unresponsive to EDA showed responses to these peptides. These four patients were responsive to pooled peptides $7-12$, and one of them also responded to pooled peptides $1-6$. Figure 6 illustrates the SI values obtained for PBMC responses to EDA and synthetic peptides 7-12 at $500 \mathrm{nmol}$ in the 15 patients with $R A$.

\section{Discussion}

Our hypothesis, an extension of that proposed by Panayi, ${ }^{1}$ is that $\mathrm{RA}$ is an autoimmune disease the initiation, perpetuation, or both, of which is dependent on $T$ cell responses to an antigen(s) from articular cartilage. Analysis of the antigenicity of aggrecan has, to date, been confined largely to measuring antigen specific T cell responses to intact PG aggregates, ${ }^{7-9}$ and has demonstrated that intact aggrecan induces minimal $T$ cell proliferation. In the present study, we have demonstrated that deglycosylated human aggrecan can significantly increase PBMC proliferation in a proportion of RA patients, and that synthetic peptides based on the aggrecan sequence can elicit a $T$ cell proliferative response.

Aggrecan was extracted and purified from human articular cartilage to measure its effects on lymphocyte proliferation in patients with $R A$ by in vitro antigen specific $T$ lymphocyte proliferation assays. The EDA was homogeneous by SDS-PAGE, with a molecular weight of $225 \mathrm{kDa}$ that is consistent with previous findings. ${ }^{25}$ Upholt et $a l^{12}$ reported that aggrecan core protein was in the size range

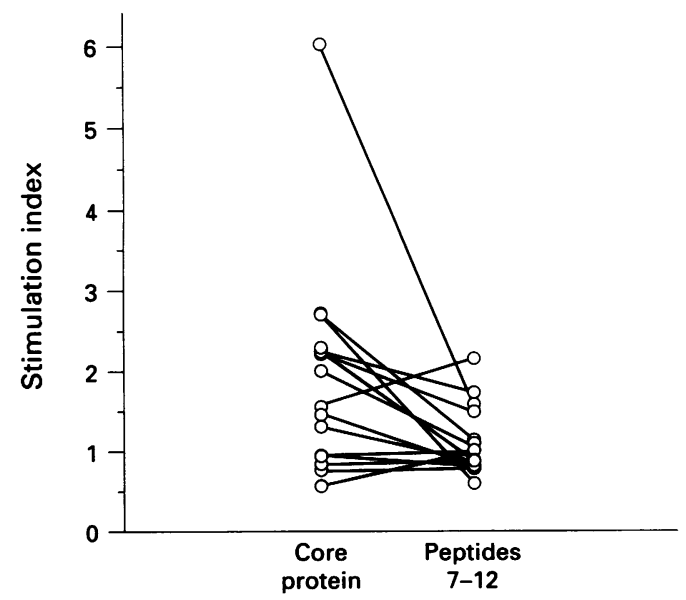

Figure 6 Stimulation index values for all the $R A$ patients $(n=15)$ challenged with enzymically deglycosylated aggrecan core protein $E D A(10 \mu \mathrm{g} / \mathrm{ml})$ and the pooled synthetic peptides (7-12) (500 nmol). 
218-248 kDa, depending on which exons were spliced into the $\mathrm{G} 3$ domain of the mRNA; this suggests that our preparation of EDA may not have an intact G3 domain. Deglycosylation of aggrecan with TFMS instead of bacterial glycosidases resulted in a reduction of its apparent molecular weight by approximately $20 \mathrm{kDa}$, to $205 \mathrm{kDa}$, with a pronounced sharpening of the electrophoretic bands, indicating that the appearance of EDA on SDS-PAGE was attributable to variability in its saccharide chains. This molecular weight also suggests that CDA may not have an intact G3 domain. Our data compare well with those of Olson et $a l^{30}$ who deglycosylated rat aggrecan with hydrogen fluoride in pyridine and identified a single $210 \mathrm{kDa}$ component. It is apparent that there is a site(s) that can be preferentially cleaved by TFMS to give two products $\left(M_{\mathrm{r}} 70 \mathrm{kDa}\right.$ and $\left.158 \mathrm{kDa}\right)$ reactive with the monoclonal antibody $12 / 21 / 1 / \mathrm{C} / 6$. As the peptides formed are similar to those obtained on cleavage of aggrecan by extracellular proteinases, ${ }^{31-33}$ it is probable that the site is in the interglobular domain.

Our studies revealed significant $\mathrm{T}$ cell proliferative responses to EDA ( $>50 \%$ increase in ${ }^{3} \mathrm{H}$-thymidine incorporation) in a greater proportion of patients with RA $(69 \%)$ than age matched controls (37\%). Similarly, TournierLasserve et $a l^{34}$ found that both patients with multiple sclerosis and age matched controls showed $T$ cell reactivity to myelin basic protein. Autoreactive $\mathrm{T}$ cells that escape deletion or clonal anergy may have a protective role and only those individuals with ineffective immunoregulatory pathways or the appropriate disease associated genetic susceptibility factors may develop damaging autoimmune responses.

PBMC from a subset of RA patients $(12 \cdot 5 \%)$ reacted to EDA with SI values above the upper threshold of the control range. While all of these patients had longstanding disease $(>10$ years), there was no significant association between the magnitude of the SI values and other parameters of disease activity (data not shown). Treatment of aggrecan with TFMS removes not only repeating disaccharide units of the GAGs, but also the $N$ and $O$-linked oligosaccharides. ${ }^{26}$ While EDA and CDA were equipotent in the stimulation of control PBMC, several patients responded to CDA with SI values more than double those to EDA. There are two possible explanations for this result: either the residual GAG/oligosaccharide units remaining after glycosidase action may be sufficient to reduce the uptake or processing of the peptide by antigen presenting cells present in the peripheral blood, or the cleavage of a proportion of the protein during chemical deglycosylation may result in the exposure of a crytic epitope, ${ }^{19}$ which would not otherwise be presented. The first hypothesis implies that there is a T cell epitope recognised by the PBMC of a proportion of RA patients closely associated with a GAG attachment sequence; the second suggests that such an epitope is associated with the TFMS sensitive cleavage site in the interglobular domain.

In the Balb/c mouse model of PG induced arthritis, ${ }^{6}$ there is evidence that $T$ cells recognise epitopes located within, or near, the CS attachment region..$^{18}$ In our study, of seven patients who demonstrated increased proliferative responses to EDA, four $(57 \%)$ also reacted to synthetic peptides based upon the 19 mer repeat present in the CS-1 region of human aggrecan. We tested $1215 \mathrm{mer}$ synthetic peptides designed to cover the range of epitopes in this region of the CS-1, in two batches (sequences given in figure 2), and found that only one patient responded to peptides 1-6, while four patients gave increased proliferative responses to peptides 7-12. Goodacre et $a l^{19}$ found that $T$ cell lines from $\mathrm{Balb} / \mathrm{c}$ mice immunised with human aggrecan were responsive to sequences EVLETAAPGVEDISGLPSG and EVLETAAPGVED from the CS-1 domain, but not to GVEDISGLPSG. It may be significant that our peptide 8 is the only peptide to contain the entire sequence found to be antigenic by Goodacre's group, but further work, using individual peptides, is necessary to define the $T$ cell epitope(s) in our patients more precisely. The study by Goodacre et $a l^{19}$ also showed that $\mathrm{T}$ cell lines responsive to the CS-1 $19 \mathrm{mer}$ did not proliferate in response to intact aggrecan, which demonstrates the limited antigen processing and presenting abilities of peripheral blood cells, and hence the limitations of proliferation assays.

All of these findings raise the possibility that degradation of PG aggregates by extracellular proteinases may influence the identity of the peptide fragments made available for binding to major histocompatibility complex molecules in antigen presenting cells (APCs). Local inflammatory processes within the joints of susceptible patients, resulting from either trauma or infection, may stimulate the production of cytokines and subsequently the extracellular proteinases that degrade aggrecan. Martin and Dean $^{35}$ have shown that PG aggregates degraded by extracellular proteinase are taken up and processed by APCs by a mechanism different than that applied to intact PG aggregate. It is possible that the pathogenicity of aggrecan may be altered by degradation which could promote the availability of cryptic immunodominant $T$ cell recognition sites. Fragments of aggrecan may be processed more efficiently by lysosomal proteinases within the APCs and have a key role in determining which epitopes dominate immune responsiveness. Furthermore, determinant spreading-both intra- and intermolecularly - could lead to a disease repertoire of $\mathrm{T}$ cells. ${ }^{36}$ Our data suggest that, at least in some patients with RA, autoimmune responses to the aggrecan core protein of articular cartilage may contribute to joint damage.

This study was funded by the Arthritis and Rheumatism Council, the Institute of Orthopaedics, Oswestry and Arthritis \& Rheumatism Trust Funds of the Robert Jones \& Agnes Hun Orthopaedic Hospital NHS Trust. 
1 Panayi G S. The immunopathogenesis of rheumatoid arthritis. $B r f$ Rheumatol 1993; 32: 4-14.

2 Champion $B$, Poole A R. Immunity to homologous cartilage proteoglycans in rabbits with chronic inflammatory arthritis. Matrix 1981; 1: 453-73.

3 Glant T T, Olah I. Experimental arthritis produced by proteoglycan antigen in rabbits. Scand $\mathcal{f}$ Rheumatol 1980 ; 9: $271-9$.

4 Glant T T. Immunology in the pathogenesis of cartilage degradation in experimental arthritis. Semin Arthritis Rheum 1981; 11: 107-8.

5 Glant T T. Induction of cartilage degradation in experimental arthritis produced by allogeneic and xenogeneic proteoglycan antigens. Connect Tissue $R e$ : 1982; 9: proteog $137-44$.

6 Mikecz K, Glant T T, Poole A R. Immunity to cartilage proteoglycans in $\mathrm{BALB} / \mathrm{c}$ mice with progressive polyarthritis and ankylosing spondylitis induced by injection of human cartilage proteoglycan. Arthritis Rheum 1987; 11: $107-8$.

7 Glant T T, Csongor J, Szücs T. Immunopathological role of proteoglycan antigens in theumatoid joint disease. Scand $\mathcal{I}$ Immunol 1980; 11: 247-52.

8 Golds E E, Stephen I B M, Esdaile J M, Strawczynski H, Poole A R. Lymphocyte transformation to connective tissue antigens in adult and juvenile rheumatoid arthritis, osteoarthritis, ankylosing spondylitis, systemic lupus erythematosus, and a non-arthritic control population. Cell Immunol 1983; 82: 196-209.

9 Sigal L H, Johnston S L, Philips P E. Cellular immune responses to cartilage components in rheumatoid arthritis and osteoarthritis: a review and report of a study. Clin Exp Rheum 1988; 6: 59-66.

10 Heinegård D, Oldberg $\AA$. Structure and biology of cartilage and bone matrix noncollagenous macromolecules. and bone matrix noncoll

11 Goodacre J A, Pearson J P. Human cartilage proteoglycans as T-cell autoantigens. Ann Rheum Dis 1992; 51: $1094-7$

12 Upholt W B, Chandrasekaran L, Tanzer M L. Molecular cloning and analysis of the protein modules of aggrecans. EXS 1994; 70: 37-52.

13 Kimura H, Tateishi $H$, Ziff $M$. Surface ultrastructure of rheumatoid articular cartilage. Arthritis Rheum 1977; 20: 1085-94.

14 Mitchell N S, Shepard N. Changes in proteoglycan and collagen in cartilage in rheumatoid arthritis. $\mathcal{f}$ Bone foint collagen in cartilage in

15 Martel-Pelletier J, Pelletier J-P, Cloutier J-M, Rebert N, Malemud C J. Proteoglycan structural changes in human rheumatoid articular cartilage. Clin Exp Rheum 1993; 10: 151-9.

16 Saxne T, Heinegård D. Synovial fluid analysis of two groups of proteoglycan epitopes distinguishes early and late cartilage lesions. Arthritis Rheum 1992; 35: 385-90.

17 Witter J, Roughley P J, Webber C, Roberts N, Keystone E, Poole A R. The immunological detection and characterisation of cartilage proteoglycan degradation products in synovial fluids of patients with arthritis. Arthritis Rheum 1987; 30: 519-29.

18 Mai A, Walcz E, Hovarth P, Glant T T. Expression of cDNA clones encoding core protein domains of mouse aggrecan FASEB ₹ 1993; 7: 140 .
19 Goodacre J A, Middleton S, Lynn S, Ross D A, Pearson J. Human cartilage aggrecan CS1 region contains cryptic T-cell recognition sites. Immunology 1993; 78: 586-91.

20 Doran M C, Goodstone N J, Hobbs R N, Ashton B A. Cellular immunity to cartilage link protein in patients with inflammatory arthritis and non-arthritic controls. Ann Rheum Dis 1995; 54: 466-70.

21 Stevens J W, Oike Y, Handley C, Hascall V C, Hampton A, Caterson B. Characterisation of the core protein of Cateron sarcoma. $f$ Cell Biochem 1984; 26: 247-59.

22 Liang M H, Medsger T A, Mitchell D M, et al. The American Rheumatism Association 1987 revised criteria for the classification of rheumatoid arthritis. Arthritis Rheum 1988; 31: 315-23.

23 Bayliss M T, Roughley P J. The properties of proteoglycan prepared from human articular cartilage by using associative caesium chloride oradients of high and low starting densities. Biochem 7 1985; 232: 111-7.

24 Bitter T, Muir H M. A modified uronic carbazole reaction. Anal Biochem 1962; 4: 330-4.

25 Oike Y, Kimata K, Shinomura T, Suzukis S. A mapping technique for probing the structure of proteoglycan core molecules. 7 Biol Chem 1982; 257: 9751-8.

26 Edge A S B, Faltynek C R, Hof L, Reichert L E, Weber P. Deglycosylation of glycoproteins by trifluoromethanesulphonic acid. Anal Biochem 1981; 118: 131-7.

27 Laemmli U K. Cleavage of structural proteins during the assembly of the head of bacteriophage T4. Nature 1970; 227: $680-5$.

28 De Moreno A, Smith J F, Smith R V. Silver staining of protein in polyacrylamide gels: increased sensitivity through a combined Coomassie blue-silver stain procedure. Anal Biochem 1985; 151: 466-70.

29 Towbin $H$ Stahelin T, Gordon J. Electrophoretic transfer of proteins from polyacrylamide gels to nitrocellulose of proteins from polyacrylamide gels to nitrocellulose sheets: procedure and some

30 Olson C A, Krueger R, Schwartz N B. Deglycosylation of chondroitin sulphate by hydrogen fluoride in pyridine. Anal Biochem 1985; 146: 232-7.

31 Vilim V, Fosang A. Characterisation of proteoglycans isolated from associative extracts of human articular cartilage. Biochem f 1993; 293: 165-72.

32 Mok M T, Ilic M Z, Handley C J, Robinson H C. Cleavage of proteoglycan aggregate by leucocyte elastase. Arch Biochem Biophys 1992; 292: 442-7.

33 Flannery $C$ R Lark M, Sandy J D. Identification of a stromelysin cleavage site within the interglobular domain stromelysin cleavage site within the interglobular domain of human aggrecan. Evidence for proteolysis at this site in vivo in hum $1008-14$.

34 Tournier-Lasserve E, Hashim G A, Bach M A. Human $T$-cell responses to myelin basic protein in multiple sclerosis and healthy subjects. $\mathcal{F}$ Neurosi Res 1988; 19: 149-56.

35 Martin H, Dean M. A proteolytic fragment from link protein is taken up and processed by monocytes and B-cells. Biochem f 1991; 280: 679-86.

36 Lehmann P V, Sercarz E E, Forsthuber T, Dayan C M, Gammon $G$. Determinant spreading and the dynamics of the autoimmune T-cell repertoire. Immunol Today 1993; the autoim $203-7$. 